\title{
RESILIENSI PADA WANITA YANG MENGALAMI ABORTUS SPONTANEA
}

\author{
Imanika Bunga Ayu \\ Psikologi,Fakultas Ilmu Pendidikan, Universitas Negeri Jakarta \\ Jakarta \\ Imanikaluphpepala@yahoo.com
}

\begin{abstract}
Abstrack
The purpose of this research is to provide a depiction of the resilience of women who had experienced spontaneous abortion.

The research method used is descriptive quantitative. The authors use questionnaires based on the dimensions of resilience resilience by Reivich \& Shatte (2002). Characteristics of the survey respondents were women who had experienced a spontaneous abortion, aged 18-40 years, and had never married. Respondents totaling 44 people were taken by purposive sampling technique. Results showed resilience try out the scale reliability scores are interpreted 0.813 resilience questionnaire is reliable. The test data is done with SPSS version 16.00.

The results of this research, indicate that the level of resilience of women who had experienced a spontaneous abortion was 27 respondents are in a high level of resilience, 17 respondents were in medium level of resilience.
\end{abstract}

\section{Keyword $\quad$ : Resilience, Women, Spontaneous Abortion}

\section{Pendahuluan}

Dewasa awal bagi seorang wanita merupakan suatu gerbang menuju tugas perkembangan yang sangat menentukan bagi masa depan kehidupan rumah tangga. Hurlock (1980) mengatakan bahwa salah satu tugas perkembangan dari wanita dewasa awal meliputi memilih seorang teman hidup, belajar hidup bersama dengan suami membentuk suatu keluarga, memiliki anak dan membesarkannya serta mengelola sebuah rumah tangga dengan baik. Hal tersebut mutlak dilakukan oleh mayoritas wanita sebagai bentuk pemenuhan kebutuhan baik secara fisik maupun secara psikologis.

Ketika wanita beranjak dewasa dan memutuskan untuk menikah dengan pasangannya, wanita cenderung memiliki harapan untuk memiliki buah hati dalam rumah tangga. Sehingga tidak sedikit dari wanita tersebut untuk tidak menunda memiliki anak. Kehamilan merupakan satu-satunya cara bagi wanita agar memiliki keturunan. Bagi sebagian 
besar wanita, kehamilan merupakan anugerah. Menurut Okun dan Rappapport, kelahiran seorang anak akan menyelamatkan pernikahan (Santrock, 2002:120). Budaya di Indonesia pun menganggap bahwa wanita dapat dikatakan sempurna jika wanita tersebut menikah, dapat merasakan hamil dan memiliki keturunan. Tidak heran jika wanita di Indonesia cenderung berpikir untuk cepat menikah dan memiliki keturunan. Kehamilan bisa menjadi pengalaman yang bisa dibagi, melibatkan lebih dari sekedar keadaan fisik seseorang wanita yang mengandung janin.

Ketika proses kehamilan tersebut terjadi, tidak selamanya kehamilan menghasilkan suatu kelahiran anak yang sehat. Banyak faktor yang mempengaruhi kondisi ibu dan janin sehingga tidak sedikit wanita yang mengalami masalah dalam kehamilannya. Salah satu permasalahannya adalah wanita mengalami keguguran atau abortus spontanea.

Abortus spontanea adalah keluarnya hasil konsepsi atau janin tanpa intervensi medis maupun mekanis sebelum janin mencapai usia kehamilan 22 minggu (Saifuddin, dkk, 2002:M11). Orang-orang awam lebih mengenal abortus spontanea dengan istilah keguguran. Faktorfaktor yang menyebabkan wanita mengalami abortus spontanea terdiri dari faktor eksternal dan faktor internal. Faktor-faktor tersebut diperjelas oleh Roeshadi (2004) yang menyatakan bahwa kemiskinan, kebodohan, ketidaktahuan, dan budaya diam wanita Indonesia, ditambah lagi oleh transportasi yang sulit dan ketidakmampuan membayar pelayanan yang baik akan menyebabkan pelayanan untuk ibu hamil di Indonesia masih kecil cakupannya, sehingga banyak kasus rujukan yang diterima di Rumah Sakit sudah sangat terlambat dan gawat sehingga sulit ditolong (Roeshandi, 2004).

Terdapat faktor-faktor medis yang melatarbelakangi terjadinya abortus spontanea, diantaranya karena wanita mengalami kelainan pertumbuhan hasil konsepsi, kelainan pada plasenta, penyakit ibu yang tiba-tiba menyerang (seperti pneumonia dan cacar), dan masih banyak lagi alasan medis yang menyebabkan wanita hamil harus mengalami abortus spontanea. Usia juga berpengaruh dengan kerentanan wanita terhadap abortus spontanea dalam kehamilannya. Wanita pada usia 25-29 tahun beresiko mengalami abortus spontanea sebesar $10,7 \%$, sementara wanita berusia 30-34 beresiko mengalami abortus spontanea sebesar $14,2 \%$ dan pada usia 35-39 tahun wanita beresiko mengalami abortus spontanea sebesar 26,2\% ("European Journal of Endocrinology",
2004). Jika melihat pada kenyataan di atas, semakin wanita dewasa secara usia, maka beresiko tinggi mengalami abortus spontanea pada kehamilannya.

Abortus spontanea berdampak secara fisik dan psikologis bagi para wanita yang mengalaminya. Dari beberapa dampaknya diantaranya : kehilangan harga diri (82\%), berteriak-teriak histeris (51\%), mimpi buruk berkali-kali mengenai bayi (63\%), ingin melakukan bunuh diri (28\%), mulai mencoba menggunakan obat-obat terlarang (41\%), tidak bisa menikmati lagi hubungan seksual (59\%) (www.aborsi.org).

Berakhirnya kehamilan akibat keguguran dapat menyebabkan timbulnya depresi. Para wanita tersebut mungkin akan kehilangan kepercayaan diri akibat merasa tidak mampu untuk mempercayai tubuh si wanita itu sendiri dan melahirkan. Merasa kehilangan, sedih, merasa kosong, marah, merasa tidak cukup, bersalah dan cemburu merupakan berbagai perasaan yang kadang-kadang dialami setelah berakhirnya kehamilan (Patel, 2001:222). Hal tersebut diperkuat dengan hasil penelitian yang menyebutkan bahwa wanita yang mengalami abortus spontanea menderita depresi, dilanda kesedihan, rasa bersalah dan kecemasan (Broen, et al, 2004).

Pernyataan sedih, cemas, takut dan merasa bersalah yang berkepanjangan dapat mengakibatkan kesehatan secara psikologis pun menjadi terganggu. Wanita-wanita ini secara alamiah tentunya akan lebih sensitif. Tetapi tuntutan untuk terus melanjutkan hidup dan merubah hidup wanita tersebut di tengah masa krisis setelah mengalami abortus spontanea menjadi suatu keadaan yang membuat wanita menjadi dilema terhadap perannya. Perlu adanya dorongan dari lingkungan eksternal untuk membangun kembali motivasi dan semangat hidup dari para wanita yang pernah mengalami abortus spontanea ini. Dukungan sosial dan moral berupa dukungan dan pendekatan personal sangat diperlukan oleh para wanita ini, disamping itu peran suami dan keluarga yang meyakinkan kebermaknaan suatu kehidupan merupakan hal yang paling penting bagi peningkatan rasa kepercayaan diri para wanita yang pernah mengalami abortus spontanea. Memberikan perhatian dan penanganan secara medik juga merupakan bagian dari cara agar membangkitkan rasa kepercayaan diri di dalam hidupnya.

Dengan dukungan yang besar, akan timbul dari wanita ini untuk melakukan adaptasi dengan hidup yang baru, menilai, mengatasi, dan meningkatkan diri ataupun mengubah dirinya dari keterpurukan dalam hidupnya, 
sehingga wanita ini memiliki keteguhan hati dan kekuatan untuk menghadapi kehidupannya baik sekarang dan untuk menjalani kehidupannya menuju ke masa depan. Kekuatan-kekuatan tersebut dapat mengantarkan individu terhadap suatu titik yang dinamakan resiliensi.

Resiliensi adalah kemampuan untuk mengatasi dengan baik perubahan hidup pada level yang tinggi, menjaga kesehatan di bawah kondisi penuh tekanan, bangkit dari keterpurukan, mengatasi kemalangan, merubah cara hidup ketika cara yang lama dirasa tidak sesuai lagi dengan kondisi yang ada, dan menghadapi permasalahan tanpa melakukan kekerasan (Siebert, 2005).

Abortus spontanea merupakan kejadian yang luar biasa bagi para wanita, bukan hanya dapat mengindikasikan kelainan dalam bentuk fisik, juga menghasilkan kondisi psikologis. Wanita tersebut dapat dikatakan resiliensi jika wanita mampu bertahan dalam keadaan tertekan, dan bahkan berhadapan dengan kesengsaraan (adversity) atau trauma yang dialami dalam kehidupannya (Reivich. K \& Shatte. A, 2002).

\section{Metode Penelitian}

Penelitian ini merupakan penelitian deskriptif kuantitatif. Teknik pengambilan sampel yang dilakukan dalam penelitian ini menggunakan teknik non-random sampling. Peneliti menggunakan kuisioner resiliensi berdasarkan dimensi resiliensi oleh Reivich \& Shatte (2002) sebanyak 50 aitem pernyataan ditambah dengan 8 pertanyaan terbuka sebagai penguat dari jawaban 50 aitem penyataan sebelumnya. Karakteristik responden penelitian adalah wanita yang pernah mengalami Abortus Spontanea, berusia 18-40 tahun, dan sudah pernah menikah. Responden berjumlah 44 orang yang diambil dengan teknik purposive sampling. Hasil try out skala resiliensi menunjukan skor reliabilitas 0,813 yang dimaknai kuesioner resiliensi adalah reliabel. Pengujian data dilakukan dengan SPSS versi 16.00 .

\section{Hasil dan Pembahasan}

\section{A. Hasil}

Dari data 44 responden tersebut dapat dilihat hasil analisis statistik berupa ukuran tendensi sentral. Ukuran tendensi sentral yang dihitung berupa mean atau rataan sebaran skor sebesar 158,77 ; median atau nilai tengah skor sebesar 159; modus atau skor yang paling banyak di dapat responden sebesar 165; standar deviasi atau skor simpangan sebesar 1,277 dan ukuran juling atau kecondongan kurva bergerak positif dengan skewness 0,426 . Range dari data sebesar 46.

Grafik 1. Sebaran Data Sampel Penelitian

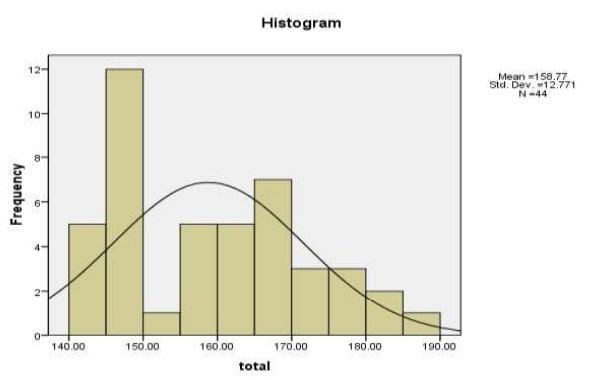

Untuk menentukan Tinggi atau rendahnya tingkat resiliensi responden, peneliti menginput data sesuai dengan hasil data yang dikumpulkan. Penentuan batas atas dan batas bawah dilakukan berdasarkan mean teoritik dari data.

Penggolongan tersebut dilakukan dengan menghitung menggunakan rumus :
a. Tinggi : $X>(\mu+1$ SD $)$
b. Sedang: $(\mu-1$ SD $)<X<(\mu+1$ SD $)$
c. Rendah : $\mathrm{X}<(\mu-1 \mathrm{SD})$

Dengan melihat hasil jawaban instrumen penelitian, skor total bergerak dari angka terendah yaitu 140, dan angka tertinggi yaitu 186. Nilai rata-rata 158,77 ; median 159 ; dan modus 165 . Terdapat 27 responden yang memiliki tingkat resiliensi yang tinggi, dan 17 responden memiliki tingkat resiliensi yang sedang. Tidak terdapat responden yang memiliki resiliensi rendah.

Secara teoritik, resiliensi terbangun atas 7 aspek, diantaranya regulasi emosi, kontrol terhadap sikap-sikap impulsif, optimisme, empati, kemampuan menganalisa masalah, efikasi diri dan pencapaian. Secara garis besar, dapat dikatakan bahwa responden yang memiliki resiliensi yang tinggi jika skor total berada di atas 150 . Sehingga responden yang dikatakan resilien adalah responden yang bersikap atau memiliki lebih dari $75 \%$ dari pernyataan yang mewakili ketujuh aspek resiliensi tersebut. Dan responden dikatakan memiliki resiliensi rendah jika responden memiliki sikap yang kurang dari $50 \%$ dari 
pernyataan yang mewakili ketujuh aspek resiliensi tersebut.

\begin{tabular}{llll}
\hline NO & KATEGORISASI & JUMLAH & PROSENTASE \\
\hline $\mathbf{1}$ & Tinggi & 27 responden & $61,36 \%$ \\
$\mathbf{2}$ & Sedang & 17 responden & $38,64 \%$ \\
$\mathbf{3}$ & Rendah & 0 responden & $0 \%$ \\
\hline
\end{tabular}

Tabel 1.

Kategorisasi Kelas Resiliensi Responden

Grafik 2. Tabulasi Nilai Resiliensi Wanita Yang Pernah Mengalami Abortus Spontanea.

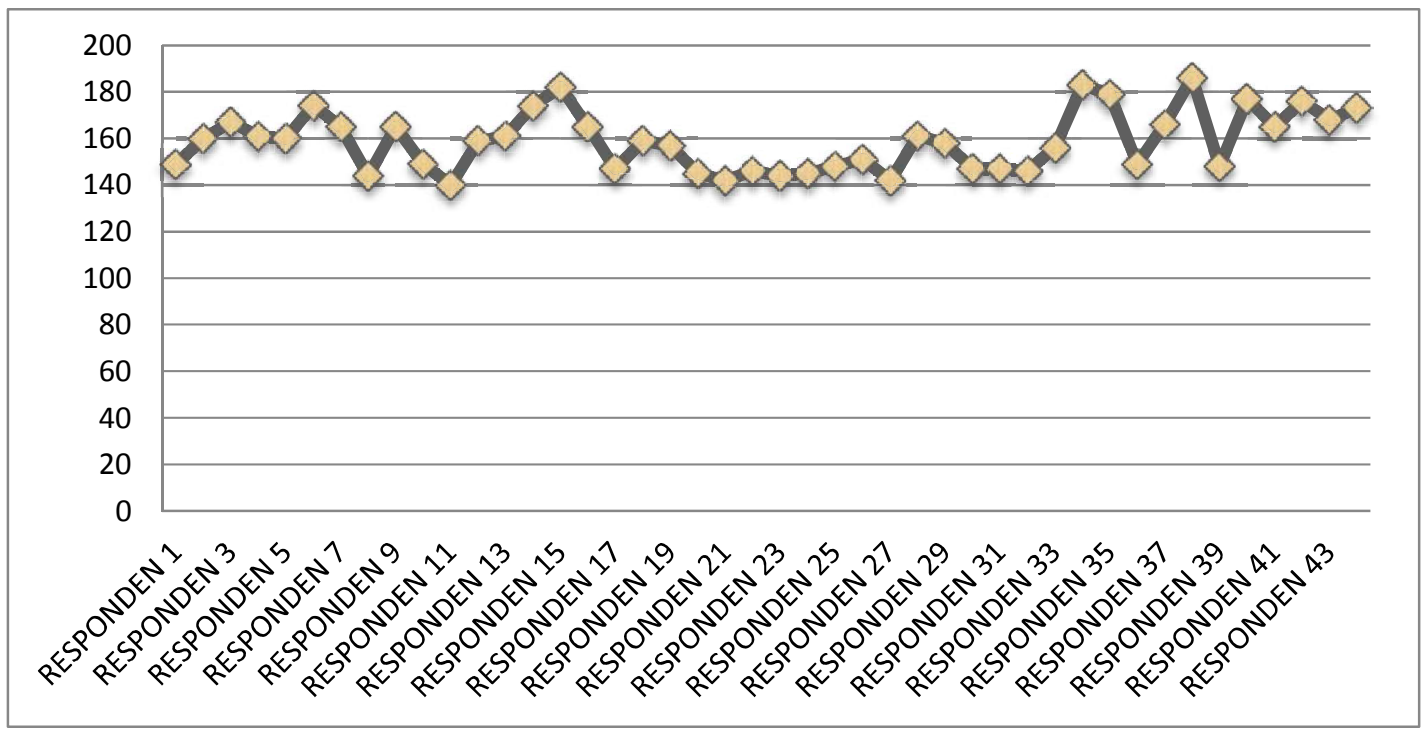

Dari pemaparan data-data di atas, jelas responden (dalam penelitian ini adalah wanita yang mengalami abortus spontanea) memiliki 2 tingkatan, yaitu tinggi dan sedang.

\section{B. Pembahasan}

Dari data demografis yang diperoleh oleh peneliti, usia wanita yang menjadi responden tersebar dari usia 21 tahun hingga 40 tahun. Hal ini sesuai dengan kodrat perkembangan wanita dewasa awal yang memiliki tugas perkembangan untuk menikah, membentuk keluarga dan memiliki anak. Nampaknya, kehamilan yang dirasakan oleh responden tidak berujung pada kelahiran anak melainkan pada peristiwa abortus spontanea. Semakin bertambah usia pada wanita, maka kehamilan akan semakin rentan terhadap masalah abortus spontanea.
Selanjutnya, dari data utama yang diperoleh oleh peneliti dapat dilihat bahwa wanita yang pernah mengalami abortus spontanea memiliki tingkat resiliensi yang cenderung tinggi dan sedang. Dari data kuantitatif menyebutkan bahwa $61,36 \%$ responden dinyatakan memiliki resiliensi tinggi dan 38,64\% responden memiliki resiliensi sedang. Dalam teori Reivich dan Shatte (2002) menyatakan bahwa orang yang memiliki resiliensi adalah orang-orang yang memiliki ketujuh aspek yang menjadi dimensi dalam penelitian ini. Aspek tersebut adalah memiliki regulasi emosi yang baik, mampu mengontrol sikap impulsif yang ada pada dirinya, bersikap optimis, mampu menganalisis masalah, memiliki empati terhadap orang lain, 
memiliki efikasi diri dan pencapaian terhadap hal-hal yang positif. Dalam pemaparan tersebut jelas bahwa wanita-wanita yang menjadi responden penelitian ini memiliki ketujuh aspek dari resiliensi tersebut.

Setiap orang mengalami kejadian traumatik dan menimbulkan stres yang tinggi, sehingga resiliensi diperlukan dalam menghadapi dan mengendalikan diri sendiri. kemunduran yang dirasakan biasanya begitu ekstrim sehingga peneliti menggunakan aitem-aitem unfavorable dalam instrumen penelitian agar dapat melihat respon dari responden terhadap pernyataan yang bersifat tidak menggambarkan ciri-ciri pribadi yang memiliki resiliensi. Pada kesempatan yang sama peneliti menggunakan aitem favorable dalam instrumen agar dapat melihat respon dari responden terhadap pernyataan yang bersifat mewakili ciri-ciri pribadi yang memiliki resiliensi. Dari hasil yang didapat dengan kecenderungan tingkat resiliensi yang tinggi dan sedang tersimpulkan bahwa responden cenderung tidak setuju dengan aitem unfavorable dan cenderung setuju dengan aitem favorable sehingga menghasilkan skor total yang tinggi dan sedang sesuai dengan batas mean teoritik yang terhitung manual.

Selain itu, sebagai penguat jawaban dari pernyataan instrumen penelitian, peneliti memberikan pertanyaan terbuka yang terkait dengan intrumen penelitian. Pertanyaan tersebut merupakan perwakilan dari ketujuh dimensi resiliensi yang digunakan untuk membentuk suatu instrumen penelitian. Dari delapan pertanyaan terbuka yang diberikan terlihat bahwa responden cenderung memiliki perasaan sedih dan kecewa. Rasa duka yang mendalam pasti ada dalam diri responden tapi ketika responden tahu bahwa responden telah mengalami abortus spontanea dan merespon kejadian tersebut dengan sedih dan kecewa, responden telah mengindentifikasi masalah, dalam konteks abortus spontanea, sehingga responden bersikap sebagaimana mestinya. Responden tidak bersikap resiliensi jika responden berlarut-larut menangisi keadaanya.

Mendekatkan diri merupakan hal yang menjadi pilihan terbanyak bagi responden untuk mengatasi perasaan tersebut sehingga responden dinilai mampu mengontrol sikap-sikap impulsif yang ada pada diri responden dengan mengendalikan diri dan berpikir jernih. Cara responden untuk mengumpulkan kekuatan untuk memiliki anak juga lebih bersifat spiritual dengan mendekatkan diri Tuhan dengan berdoa, ikhtiar, dsb. Hal tersebut merupakan gambaran bahwa responden mampu mengatasi permasalah dengan keyakinan dan kekuatan yang dimiliki oleh pribadi sehingga responden cenderung memiliki efikasi diri. Cara mengumpulkan kekuatan menjadi penguat aitem 44 pada instrumen penelitian. Keyakinan responden untuk memiliki momongan juga terbilang tinggi mencapai $90 \%$ - 100\%. Hal tersebut menggambarkan bahwa ada harapan dan sikap optimis pada diri responden yang menjadi ciri utama pribadi yang resilien.

Responden juga memiliki regulasi emosi yang baik dengan bersikap biasa saja terhadap lingkungan dan menghilangkan kecanggungan karena telah mengalami abortus spontanea. Ketika responden mengalami abortus spontanea, responden juga langsung mengetahui apa yang orang terdekat responden rasakan sehingga dapat dikatakan bahwa responden memiliki empati di dalam dirinya. Responden juga mampu mengambil hikmah positif dari kejadian abortus spontanea yang pernah dialami sehingga responden dapat dikatakan memiliki pencapaian dalam diri terkait dengan aitem 45 . Responden memiliki harapan untuk rumah tangganya, tentunya berupa hal-hal positif yang diharapkan mewarnai rumah tangga responden setelah kejadian abortus spontanea yang responden alami. Hal tersebut mampu melihat bahwa responden memiliki sikap optimisme yang baik terhadap rumah tangga (baik dari segi keluarga, keturunan, ekonomi, sosial) dan dirinya sendiri.

Menurut Reivich and Shatte (2002), resiliensi berguna untuk mengatasi pengalaman negatif, stres, atau menyembuhkan diri dari trauma, juga berguna untuk mendapatkan pengalaman hidup yang lebih kaya dan bermakna serta berkomitmen dalam mengejar pembelajaran dan pengalaman baru. Ketika responden mampu menarik hikmah dari suatu persitiwa, pasti individu tersebut telah belajar dan berusaha menjadi pribadi yang lebih baik. Hal tersebut dapat mereduksi pengalaman negatif, stres dan menyembukan diri dari trauma sehingga responden dapat kembali melanjutkan hidupnya. Kehidupan berlanjut dengan sikapsikap optimis yang dibangun dengan berlandaskan pada kemampuan meregulasi emosi, efikasi diri, kontrol sikap, mahir menganalisis masalah, berempati dan mau belajar dari pengalaman maka muncul pribadi yang baru yang mampu bersikap positif dan mencapai suatu pencapaian yang positif dalam hidupnya.

Selanjutnya, dari jawaban-jawaban pernyataan pada instrumen dan pertanyaan terbuka dihasilkan jawaban yang cenderung konsisten sehingga peneliti tidak meragukan jawaban responden baik dalam pernyataan dalam aitem maupun pertanyaan dalam pertanyaan terbuka. 


\section{Kesimpulan}

Dari hasil penelitian yang sudah dilakukan, tergambar tingkatan resiliensi pada wanita yang pernah mengalami abortus spontanea. Berdasarkan 44 responden yang mewakili populasi, hasil yang didapat bahwa tingkat resiliensi wanita yang mengalami abortus spontanea adalah pada kategori tingkat tinggi dan kategori tingkat sedang. Tidak ada responden yang tergolong kategori tingkat rendah pada penelitian ini.

\section{Daftar Pustaka}

Anonim. (2010). Modul Pelatihan SPSS. Jakarta : Pusat Pengembangan Teknologi Informasi UNJ. h. 32-40.

Armeini, A. (2010). Modul Analisis Data Penelitian Kuantitatif dengan SPSS. Jakarta : Program Studi Psikologi UNJ. h.7-19.

Aronson, E., Wilson, T. D., \& Akert, R. M. (2007). Social Psychology. New Jersey : Pearson Education, Inc. p. 485.

Azhari. (2002, Juni). Seminar Kelahiran Tidak diinginkan (aborsi) Dalam Kesejahteraan Reproduksi Remaja, Palembang : Fakultas Kedokteran Universitas Sriwijaya.

Azwar, S. (2009). Dasar-Dasar Psikometri. Yokyakarta : Pustaka Pelajar.

Azwar, S. (2010). Penyusunun Skala Psikologi. Yokyakarta : Pustaka Pelajar. h.51-59

Bernas. (2011, Mei 31). Tiap Tahun 3,5 Juta Wanita Keguguran. Retrieved April 29, 2012. from www.bkkbn.go.id: http://kepri.bkkbn.go.id/berita/.

Beutel, M. E., et al. (2010, March). Life Satisfaction, Anxiety, Depression, and Resilience Across the Life Span of Men. Journal of The Aging Male, 13(1): 32-39.

Broen, et al. (2004). Psychological Impact on Women of Miscarriage Versus Induced Abortion : A 2-Year Follow-up Study. Psychosomatic Medicine (2004) 66:265-271.

Creswell, J.W. (2010). Reserach Design Pendekatan Kualitatif, Kuantitatif dan Mixed, 3rd ed, (terj.). Yokyakarta : Pustaka Pelajar. h.216-225.

Desmita. (2010). Psikologi Perkembangan. Bandung : PT.Remaja Rosdakarya. h. 226-231.

Hadi, S. (2004). Metodologi Research Jilid I. Yokyakarta: Andi Yokyakarta. h. 8991
Hamilton, P.M. (1995). Dasar-Dasar Keperawatan Maternalis (Ni Luh Gede Yasmin Asih, Penerjemah). Jakarta : Penerbit Buku Kedokteran EGC. h.102.

Hurlock, E.B. (1980). Psikologi Perkembangan. Jakarta : Erlangga. h. 245-272.

Kerlinger, F. (2006). Asas-Asas Penelitian Behavioral. Edisi ketiga (terj.). Yokyakarta : Gajah Mada University Press. h.660.

Kusmaryanto, C.B. (2002). Kontroversi Abortus. Jakarta : PT. Grasindo. h.1947.

Mansjoer, A., et al. (2001). Kapita Selekta Kedokteran. Jakarta : Media Aesculapis. h.260-261.

Norman, E,. (eds.), 2000, Resiliency Enhancement : Putting The Strengths Perspective Into Social Work Practice. New York : Columbia University Press. http://ebooksclub.org.

Noviastuti \& Fidianty, A. (2010). Kecemasan Pada Wanita Hamil Pasca Abortus. Jurnal No. 4, Januari-Juni 2010. Media Medika Muda.

Patel, V. (n.d.). Ketika Tidak Ada Psikiater, Buku Panduan Pelayanan Kesehatan Jiwa (terj.). Aceh : The Royal College of Psychiatrist. h.222.

Prummel, M. F., \& Wiersinga, W. M. (2004). Thyroid Autoimmunity And Miscarriage. European Journal of Endocrinology (2004) $150 \quad 751-755$. From http://www.ncbi.nlm.nih.gov/pubmed/1 1786691.

Reivich, K \& Shatte A. (2002). The Resilience Factor. New York : Broadway Books, Random House, Inc. p.9-47.

Resiko Aborsi. (n.d.). Retrieved February 11, 2012. http://aborsi.org/resiko.htm.

Rinaldi. (2010). Resiliensi Pada Masyarakat Kota Padang Ditinjau Dari Jenis Kelamin. Jurnal Psikologi Volume 3, No. 2, Juni 2010

Roeshadi, H. (2004). Ganguan dan Penyulit pada Masa Kehamilan. Medan : Fakultas Kedokteran Universitas Sumatera Utara. From http://library.usu.ac.id/download/fk/obs tetri-haryono.pdf.

Saifuddin, B. A., dkk. (2002). Buku Panduan Pelayanan Kesehatan Maternal dan Neonatal. Jakarta: Yayasan Bina Pustaka Sarwono Prawirohardjo. h.M$11-\mathrm{M}-13$. 
Santrock, J.W. (2002). Life-Span Development: Perkembangan Masa Hidup, 5rd ed,. Jakarta: Erlangga. p. 71-92.

Sastrawinata, S, et al. (2005). Obstetri Patologi, Ilmu Kesehatan Reproduksi, edisi II,. Jakarta : Penerbit Buku Kedokteran EGC. h. 1-9.

Sedgh, G. \& Ball, H. (2008). Aborsi di Indonesia. Seri 2008, No.2. New York. Retrieved April 29, 2012. from www.guttmacher.org info@guttmacher.org.

Siebert, Al. (2005). The Resiliency Advantages. California : Berrett-Koehler Publisher, Inc. http://www.bkconnection.com.

Statistik aborsi. (n.d.). Retrieved February 11, 2012.

http://www.aborsi.org/statistik.htm.

Sudaryanto. (2007). Resiliensi dan Locus of Control Guru dan Staf Sekolah Pasca Gempa. Jurnal Kependidikan No.1, Mei 2007.

Sugiyono. (2011). Metode Penelitian Pendidikan. Bandung : Alfabeta. $\mathrm{h}$ 207-208.
Suryaratri, R.D. dan Armeini, A. (2009). Statistik Deskriptif : Statistika Dasar Psikologi dan Pendidikan. Jakarta : Program Studi Psikologi UNJ.

UNDP. Human Development Index Tren Report 2011. Retrieved February 11, 2012. From www.undp.org : http://hdr.undp.org/en/statistics/hdi/.

UNDP. Human Development Report 2011 Sustainability and Equity: A Better Future for All. Retrieved Ferbruary 11, 2012. From www.undp.org: http://hdr.undp.org/en/media/HDI2008 Tables.xls.

Wijanarko, B. (n.d.). Presentasi Mengenai Abortus. Jakarta: Fakultas Kedokteran dan Kesehatan UMJ.

Wiknjosastro, H. et al. (2006). Ilmu Kebidanan (Edisi Ketiga). Jakarta : Yayasan Bina Pustaka Sarwono Prawirohardjo. h. 302-312.

Wingo, A. P., Fani, N., Bradley, B., \& Ressler, K. J. (2010). Psychological Resilience And Neurocognitive Performance In A Traumatized Community Sample. Journal of Depression And Anxiety 27 : 768-774

(2010). 